\title{
FvbA is required for vibriobactin utilization in Pseudomonas aeruginosa
}

\author{
Sivan Elias, Elena Degtyar and Ehud Banin
}

Correspondence

Ehud Banin

ehud.banin@biu.ac.il

Received 14 September 2010

Revised 13 April 2011

Accepted 28 April 2011
The Bacterial Biofilm Research Laboratory, The Institute for Nanotechnology and Advanced Materials, The Mina and Everard Goodman Faculty of Life Sciences, Bar-Ilan University, Ramat Gan 52900, Israel

\begin{abstract}
Bacteria acquire iron through a highly specific mechanism involving iron-chelating molecules termed siderophores. The Gram-negative bacterium Pseudomonas aeruginosa can utilize siderophores produced by other micro-organisms to facilitate iron uptake. Here we show that a $P$. aeruginosa strain deficient in siderophore production can use the Vibrio cholerae siderophore vibriobactin as an iron source. In addition, we identified a $P$. aeruginosa gene, PA4156 (fvbA), encoding a protein highly homologous to the $V$. cholerae vibriobactin receptor (ViuA). A $P$. aeruginosa mutant in the two endogenous siderophores (pyoverdine and pyochelin) and in $f v b A$ was unable to utilize vibriobactin as an iron source. Additionally, preliminary analyses revealed the involvement of vibriobactin, Fur protein and an IcIR-type regulator, FvbR (PA4157), in fvbA regulation.
\end{abstract}

\section{INTRODUCTION}

Iron is an essential element for nearly all known organisms, including most bacteria, which require iron for survival and growth. For pathogenic bacteria, iron acquisition is a major challenge, since this metal exists in insoluble mineral complexes or bound to mammalian high-affinity ironbinding proteins (Skaar, 2010). Therefore, bacteria have developed several mechanisms to obtain iron. One such system consists of iron-specific chelators termed siderophores (for a recent review, see Chu et al., 2010). Under iron-limiting conditions, bacteria synthesize and secrete siderophores into the environment. The ferric siderophore is transported, in an energy-dependent manner, into the cell through a highly specific receptor protein located in the outer membrane (Braun \& Hantke, 2011; Cornelis et al., 2008; Noinaj et al., 2010). In Gram-negative bacteria, the transport of the ferric siderophore is driven by the TonBExbB-ExbD protein complex that couples cytoplasmic membrane electrochemical potential to the outer membrane receptor (Noinaj et al., 2010). The expression of the TonB-dependent siderophore receptor is tightly regulated by the level of iron (Noinaj et al., 2010). Furthermore, in several cases, the siderophore itself acts as a signal and induces the expression of its cognate receptor (Beare et al., 2003; Llamas et al., 2006; Neilands, 1995). The binding of the siderophore to its receptor induces the expression of

Abbreviations: ECF sigma factor, extracytoplasmic function sigma factor; EDDA, ethylenediamine di-ortho-hydroxyphenylacetic acid; FURTA, Fur titration assay.

Two supplementary figures are available with the online version of this paper. various genes, including genes required for siderophore uptake, and can be regulated through several regulatory pathways. One of the mechanisms involves an extracytoplasmic function (ECF) sigma/anti-sigma factor system (Visca et al., 2002). For example, in Escherichia coli, ferric citrate binds to an outer membrane receptor, FecA, that transmits the signal across the membrane to a transmembrane anti-sigma factor, FecR. This induces a conformational change, which allows the release of the FecI sigma factor protein from FecR, leading to activation of transcription of the fecABCDE operon (Braun et al., 2005). Another regulatory pathway involves two-component systems, for example $\mathrm{PfeS} / \mathrm{R}$, which are required for the enterobactin-dependent production of the ferrienterobactin receptor PfeA in Pseudomonas aeruginosa (Dean \& Poole, 1993). Finally, Arc-type transcription regulators have been shown to regulate the synthesis of siderophores and siderophore receptors. In P. aeruginosa, the AraC-type regulator PchR activates the expression of both the pyochelin and the ferripyochelin receptor (Heinrichs \& Poole, 1996). These various mechanisms enable bacteria to directly respond to the binding of a specific siderophore and to tightly regulate the expression of relevant genes.

The opportunistic pathogen $P$. aeruginosa is known to produce and utilize two chemically distinct siderophores, pyochelin (Cox, 1980) through the FptA receptor (Ankenbauer \& Quan, 1994; Hoegy et al., 2009; Michel et al., 2007), and pyoverdine (Cox \& Adams, 1985) through two receptors, FpvA and FpvB (Poole et al., 1993; Schalk, 2008). In addition to its endogenous siderophores, $P$. aeruginosa can utilize siderophores produced by other micro-organisms. It has been shown that $P$. aeruginosa has 
two receptors that mediate the uptake of the E. coli siderophore enterobactin, PfeA and PirA (Dean \& Poole, 1993; Ghysels et al., 2005). In addition, $P$. aeruginosa is capable of utilizing the Mycobacterium paratuberculosis siderophore mycobactin through FemA (Llamas et al., 2008), ferrichrome through FiuA, ferrioxamine through FoxA (Llamas et al., 2006), citrate through FecA (Cox, 1980), aerobactin through ChtA (Cuív et al., 2006), and the siderophores cepabactin (Mislin et al., 2006), desferrichrysin, desferricrocine and coprogen (Meyer, 1992) through unidentified receptors. It is interesting to note that the above-mentioned receptors probably represent only a part of the total iron-acquisition potential of $P$. aeruginosa. An in silico analysis of the $P$. aeruginosa genome has revealed an impressive total of 34 genes encoding putative TonB-dependent outer membrane receptors (Cornelis \& Matthijs, 2002). However, only a fraction of these genes have been experimentally validated thus far. Combined with the endogenous siderophores, the utilization of heterogeneous siderophores may provide $P$. aeruginosa with the ability to 'steal' iron from other micro-organisms, providing a competitive advantage in the environment.

The facultative anaerobic bacterium Vibrio cholerae produces only one known catechol siderophore, called vibriobactin (Griffiths et al., 1984). Since both V. cholerae and $P$. aeruginosa are common in aquatic environments, we investigated whether $P$. aeruginosa can utilize vibriobactin for iron uptake. In the current study we show that $P$. aeruginosa can utilize vibriobactin, a siderophore produced by $V$. cholerae, as an iron source when grown in irondeficient medium, through a newly identified receptor, FvbA (PA4156). Additionally, we show that $f v b A$ expression is tightly regulated by Fur, by vibriobactin itself as well as by an IclR-type regulator, FvbR (PA4157).

\section{METHODS}

Bacterial strains and growth conditions. Bacterial strains and plasmids used in this study are listed in Table 1. M9 minimal medium was used as a low-iron medium (Becton Dickinson; containing $0.4 \%$ glucose, $2 \mathrm{mM} \mathrm{MgSO}_{4}, 0.1 \mathrm{mM} \mathrm{CaCl}$ ). The iron chelator ethylenediamine di-ortho-hydroxyphenylacetic acid (EDDA; Fluka) was added to the growth medium to induce iron starvation. Purified siderophores (EMC Microcollections $\mathrm{GmbH}$ ) were dissolved in double-distilled water (deferoxamine and ferrichrome), methanol (vibriobactin; Bio-Lab) or DMSO (enterobactin and aerobactin; Sigma). For induction of $f v b R$ overexpression, arabinose was added to a final concentration of $1 \mathrm{mM}$.

Construction of $\boldsymbol{P}$. aeruginosa strains. The triple mutant $P A O 1 \Delta p v d D \Delta p c h E F$ fvbA: : pSE-PA4156IS was constructed as follows: a $420 \mathrm{bp}$ DNA fragment corresponding to a region at the middle of $f v b A$ gene was amplified and cloned into the TOPO cloning vector (Invitrogen) using 5'-AAGCTTTTCTCCCACAACGACAACAA-3' and $5^{\prime}$-TCTAGACTAGAAGGTGCCCTTGATGC-3' as primers. The resulting plasmid, pSE-PA4156IS, was constructed in E. coli DH5 $\alpha$, purified, and transferred into $P$. aeruginosa $P A O 1 \Delta p v d D \Delta p c h E F$ by electroporation (Choi \& Schweizer, 2006). Transconjugates were selected on LB agar (Becton Dickinson) containing carbenicillin $\left(200 \mu \mathrm{g} \mathrm{ml}^{-1}\right)$, resulting in a marked PAO1 $\Delta p v d D \Delta p c h E F$ fvbA:: pSE-PA4156IS (PASE2) strain.

For fvbA complementation, the fvbA gene (coordinates $4653103-$ 4650208 on the P. aeruginosa chromosome) was amplified by PCR

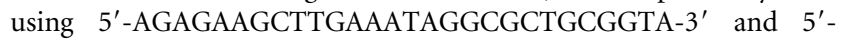
AGAGGGATCCGATGCCTTCGATGTTGCTGT- $3^{\prime}$ as primers. The PCR product was digested with HindIII and BamHI and ligated with HindIII/BamHI-digested pUCP18. The resulting plasmid, pSEPA4156COM, was purified and transferred into PAO1 $\Delta p v d D \Delta p c h E F$ fvbA::pSE-PA4156IS (PASE2) strain by electroporation (Choi \& Schweizer, 2006) to create strain PASE3.

The $f v b A-g f p$ promoter fusion strain was constructed as follows: a fragment containing the $f v b A$ promoter $(500 \mathrm{bp}$ upstream from the $f v b A$ start codon; coordinates $4650374-4650874$ on the P. aeruginosa chromosome) was amplified by PCR using $5^{\prime}$-AAAAGCTTAGGTCGTAGAGACCGCTGAG-3' and $5^{\prime}$-AAGAATTCGCGTTCAAGGATCTTCTCCA-3' as primers. The PCR product was digested with HindIII and EcoRI and ligated with a HindIII/EcoRI-digested plasmid with a $g f p$ transcription fusion in mini-CTX to create pSEPR4156GFP. This plasmid was constructed in E. coli DH5 $\alpha$, purified and transferred into $E$. coli SM10 (by chemical transformation). The plasmid was mobilized from E. coli SM10 into P. aeruginosa PAO1 by conjugation. Transconjugates were selected on Pseudomonas Isolation Agar (Becton Dickinson) containing tetracycline $\left(100 \mu \mathrm{g} \mathrm{ml}^{-1}\right)$. The insertion was confirmed by PCR analysis. One transconjugate, PASE4, was further characterized for its GFP expression.

The triple mutant PAO1 $\Delta p v d D \Delta p c h E F$ PA4157::pSE-PA4157IS was constructed as follows: a 395 bp DNA fragment corresponding to a region at the middle of PA4157 gene was amplified by PCR using 5' ATATGAATTCCTCAGCGGTCTCTACGACCT- ${ }^{\prime}$ and $5^{\prime}$-ATATAAGCTTAGCAGGTGGCTGGTCAGTT-3' as primers. The PCR product was digested with HindIII and EcoRI and ligated with HindIII/ EcoRI-digested pEX18Amp. The resulting plasmid, pSE-PA4157IS, was constructed in E. coli $\mathrm{DH} 5 \alpha$, purified, and transferred into $P$. aeruginosa $P A O 1 \Delta p v d D \Delta p c h E F$ by electroporation (Choi \& Schweizer, 2006). Transconjugates were selected on LB agar (Becton Dickinson) containing carbenicillin $\left(200 \mu \mathrm{g} \mathrm{ml}^{-1}\right)$, resulting in a marked PAO1 $\Delta p v d D \Delta p c h E F$ fvbR:: pSE-PA4157IS strain (PASE7).

Strain PASE6, which overexpresses PA4157, was constructed as follows: a 805 bp DNA fragment containing the PA4157 gene (coordinates $4652714-4653518$ on the P. aeruginosa chromosome) was amplified by PCR using 5'-TATAGAATTCATGCCGGACGCCCCGG-3' and ' 5'-ATATGGATCCGCCGGGCTGAGGTGGCTC-3' as primers. The PCR product was digested with EcoRI and BamHI and ligated with EcoRI/BamHI-digested pJN105 plasmid to create pED-PA4157OE. This places the $f v b A$ gene under the arabinoseinducible promoter $\mathrm{P}_{\mathrm{BAD}}$. The resulting plasmid was constructed in E. coli $\mathrm{DH} 5 \alpha$, purified, and transferred into $P$. aeruginosa PAO1 $\Delta p v d D \Delta p c h E F$ by electroporation (Choi \& Schweizer, 2006), and transconjugates were selected on LB agar (Becton Dickinson) containing carbenicillin $\left(200 \mu \mathrm{g} \mathrm{ml}^{-1}\right)$.

RNA isolation, RT-PCR, and real-time PCR analysis. PASE1, PASE5 and PAO1 overnight cultures were diluted into fresh M9 minimal medium to $\mathrm{OD}_{595} 0.01$ and grown to mid-exponential phase $\left(\mathrm{OD}_{595} 0.5\right)$ twice. The culture was then distributed into fresh tubes and EDDA $\left(25 \mu \mathrm{g} \mathrm{ml}^{-1}\right), \mathrm{FeCl}_{3}(100 \mu \mathrm{M})$ or vibriobactin $(2.5 \mu \mathrm{M})$ was added and cultures were grown for an additional $3 \mathrm{~h}$. RNAprotect Bacteria Reagent (Qiagen) was added to stabilize the RNA. Total RNA was isolated using an RNeasy spin column (including an on-column DNase I step) according to the manufacturer's instructions (Qiagen). cDNA was synthesized from $2 \mu \mathrm{g}$ RNA using the SuperScript II Synthesis System and random hexamers (Invitrogen). Real-time PCR was performed using a StepOnePlus 
Table 1. Strains and plasmids used in this study

Abbreviations: $A m p^{r}$, ampicillin resistance; $\mathrm{Carb}^{\mathrm{r}}$, carbenicillin resistance; $\mathrm{Gm}^{\mathrm{r}}$, gentamicin resistance; $\mathrm{Km}^{\mathrm{r}}$, kanamycin resistance.

\begin{tabular}{|c|c|c|}
\hline Strain or plasmid & Description & Reference or source \\
\hline \multicolumn{3}{|c|}{ P. aeruginosa strains } \\
\hline $\mathrm{PAO1}$ & Wild-type & Holloway et al. (1979) \\
\hline PASE1 & $\mathrm{PAO} 1 \Delta p v d D \Delta p c h E F$ & Banin et al. (2005) \\
\hline PASE2 & $\mathrm{PAO} 1 \Delta p v d D \Delta p c h E F f v b A::$ pSE-PA4156IS & This study \\
\hline PASE3 & $\mathrm{PAO} 1 \Delta p v d D \Delta p c h E F f v b A::$ pSE-PA4156IS carrying pSE-PA4156COM & This study \\
\hline PASE4 & $\mathrm{PAO} 1 \Delta p v d D \Delta p c h E F$ carrying pSE-PR4156GFP & This study \\
\hline PASE5 & PAO1, ISphoA/hah PA4157 & Jacobs et al. (2003) \\
\hline PASE6 & $\mathrm{PAO} 1 \Delta p v d D \Delta p c h E F$ carrying pED-PA4157OE & This study \\
\hline PASE7 & $\mathrm{PAO} 1 \Delta p v d D \Delta p c h E F$ fvbR::pSE-PA4157IS & This study \\
\hline \multicolumn{3}{|l|}{ E. coli strains } \\
\hline $\mathrm{DH} 5 \alpha$ & $\mathrm{F}^{\prime}$ endA1 hsdR17 supE44 thi-1 recA1 gyrA relA1 $\Delta$ (lacZYA-argF) U169 deoR & Woodcock et al. (1989) \\
\hline SM10 $\lambda$ pir & thi-1 thr leu tonA lacY supE recA:: RP4-2-Tc:: $\mathrm{Mu} \mathrm{Km}^{\mathrm{r}} \lambda$ pir & de Lorenzo \& Timmis (1994) \\
\hline $\mathrm{H} 1717$ & $\operatorname{aroB}$ fhuF:: $\lambda$ plac $\mathrm{Mu}$ & Leoni et al. (1996) \\
\hline ECSE3 & H1717 carrying pSE-pvdSFURTA & This study \\
\hline ECSE1 & H1717 carrying pSE-4156FURTA1 & This study \\
\hline ECSE2 & H1717 carrying pSE-4156FURTA2 & This study \\
\hline \multicolumn{3}{|l|}{ Plasmids } \\
\hline pUCP18 & Broad-host-range cloning vector; $A m p^{r}$ & Schweizer (1991) \\
\hline pSE-PA4156COM & pUCP18 carrying $f v b A$ gene for complementation; Carb $^{r}$ & This study \\
\hline TOPO-TA & PCR product cloning vector; $A m p^{r}$ & Invitrogen \\
\hline pSE-PA4156IS & $\begin{array}{l}\text { TOPO carrying } 420 \text { bp PCR product corresponding to a region in } \\
\text { P. aeruginosa } f v b A \text { fragment; } \text { Carb }^{r}\end{array}$ & This study \\
\hline $\operatorname{mini}-\mathrm{CTX} 1$ & Self-proficient integration vector with tet, V-FRT-attPMCS, ori, int and oriT; $\mathrm{Tc}^{\mathrm{r}}$ & Hoang et al. (2000) \\
\hline pSE-PR4156GFP & $f v b A$ promoter-gfp transcription fusion in Mini-CTX-lacZ; $\mathrm{Tc}^{\mathrm{r}}$ & This study \\
\hline pJN105 & araC-pBAD (broad-host-range vector); $\mathrm{Gm}^{\mathrm{r}}$ & Newman \& Fuqua (1999) \\
\hline pED-PA4157OE & pJN105 carrying PA4157 gene for overexpression; Carb ${ }^{r}$ & This study \\
\hline pBR322 & Broad-host-range cloning vector; $A m p^{r}$ & Covarrubias \& Bolivar (1982) \\
\hline pSE-4156FURTA1 & pBR322 carrying PA4156 full-length promoter; Amp ${ }^{r}$ & This study \\
\hline pSE-4156FURTA2 & pBR322 carrying PA4156 truncated promoter; $A m p^{r}$ & This study \\
\hline pSE-pvdsFURTA & pBR322 carrying $p v d S$ promoter; Amp ${ }^{r}$ & This study \\
\hline pEX18Amp & Broad-host-range gene replacement vector; $s a c B ; A^{2} p^{r}$ & Hoang et al. (1998) \\
\hline pSE-PA4157IS & $\begin{array}{l}\text { pEX18 Amp carrying } 395 \text { bp PCR product corresponding to a region in } \\
\text { P. aeruginosa PA4157 fragment; Carb }\end{array}$ & This study \\
\hline
\end{tabular}

Real-Time PCR system (Applied Biosystems). The $20 \mu \mathrm{l}$ PCR included $15 \mathrm{ng}$ cDNA, $1 \times$ Fast SYBR Green Master Mix (Applied Biosystems) and $0.4 \mu \mathrm{M}$ each primer. The primer pairs used were: pvdS-RT-PCR-58F (5'-GATAACCGTACGATCCTGGTGAAT-3') and pvdS-RT-PCR-138R (5'-CGCATCCTGGACCACATCTT-3'), PA4156RT-PCR-1920F (5' -CGCCAGCTACCGCTTCAA-3') and PA4156-RTPCR-2013R (5'-CCGGTTTTCCTGCATGTAGGT-3'), PA1684-2F (5' TGAGCAGCCTTACCGTCTATCA- $\left.3^{\prime}\right)$ and PA1684-88R (5' -CCAGGGTCGAAGCGATGT-3'), PA4157-RT-PCR370F (5'-TGGTACCGCAGCGCCTAT-3') and PA4157-RT-PCR437R (5'-GTATTGTCGATGGGCAGGATATC-3'), and pfeA-RT-PCR-F (5'-CTACGGGCAAAGCACCAGTT-3') and pfeA-RT-PCR-R (5'-GCTGTACTCGATGCCCAGTTC-3'). The reactions were performed in Optical 8-Tube Strips (Applied Biosystems) at $95{ }^{\circ} \mathrm{C}$ for $20 \mathrm{~s}$, followed by 40 cycles of $95{ }^{\circ} \mathrm{C}$ for $30 \mathrm{~s}$ and $60{ }^{\circ} \mathrm{C}$ for $30 \mathrm{~s}$. Data were collected after each cycle. Following the PCR, a melting curve was performed from 60 to $95{ }^{\circ} \mathrm{C}$. A standard curve was performed for each primer pair to check the efficiency of the reactions.

Construction of Fur consensus logo. Fur binding sequences of 36 iron-regulated genes in $P$. aeruginosa, identified by two microarray studies (Ochsner et al., 2002; Palma et al., 2003), were extracted from a cooperative Fur binding model designed by van Oeffelen et al. (2008). The sequence logo was generated using Weblogo at http:// weblogo.berkeley.edu.

Fur titration assay (FURTA). FURTA was performed as described by Stojiljkovic et al. (1994). The putative promoter region $\mathrm{P}_{f v b A}$ was amplified by PCR using 5'-GGCTGCGAAGTATTCAACG- ${ }^{\prime}$ and $5^{\prime}$ GCAGGGTGGACAGCGTGAC-3' as primers to obtain a 305 bp fragment containing the full-length promoter including the predicted Fur box, and $5^{\prime}$-GGCTGCGAAGTATTCAACG-3' and $5^{\prime}$-GGATCTTCTTTTTCCATTCAGGCTATCACGCCACC-3' as primers to obtain a $214 \mathrm{bp}$ fragment containing the truncated promoter without the Fur box. PCR products were cloned into EcoRV-digested pBR322 (NEB) to create pSE-4156FURTA1 and pSE-4156FURTA2. The resulting plasmids were transformed into E. coli $\mathrm{H} 1717$ and sequenced. E. coli H1717 strains carrying plasmids were grown on MacConkey lactose agar (Difco) supplemented with $100 \mu \mathrm{M}$ ampicillin and different $\mathrm{FeCl}_{3}$ concentrations (0, 20, 40, 50, 60, 70, 120 or $150 \mu \mathrm{M})$, and colony phenotype was examined after $24 \mathrm{~h}$ incubation at $37^{\circ} \mathrm{C}$. Red colonies $\left(\mathrm{Lac}^{+}\right)$indicate Fur protein binding to the Fur box in the promoter region. The promoter of $p v d S$ (from base pairs 2721925 to 2722175 ) cloned into pBR322 (pSE-pvdSFURTA) and 
transformed into E. coli $\mathrm{H} 1717$ served as a positive control for the FURTA experiment.

\section{RESULTS AND DISCUSSION}

\section{Vibriobactin supports the growth of a $\boldsymbol{P}$. aeruginosa siderophores mutant under iron- deficient conditions}

It is known that strains of $P$. aeruginosa deficient in pyoverdine and pyochelin production fail to grow in ironlimited minimal medium containing the synthetic iron chelator EDDA, probably because they are incapable of utilizing EDDA-bound iron for growth (Ankenbauer et al., 1986). Based on this phenotype, we examined the ability of a $P$. aeruginosa mutant in siderophores production to grow in the presence of the $V$. cholerae siderophore vibriobactin and EDDA. The $P$. aeruginosa double mutant in the $p v d D$ and $p c h E F$ genes (PASE1) was grown in iron-deficient minimal medium with and without EDDA, or EDDA and vibriobactin. As mentioned above, EDDA inhibited the growth of the $P$. aeruginosa PASE1 mutant compared with the wild-type PAO1 (Fig. 1, black bars). However, the addition of vibriobactin restored the growth of this mutant in EDDA-containing medium (Fig. 1, grey bars). This result suggests that $P$. aeruginosa can utilize vibriobactin as an iron source, perhaps through a vibriobactin-specific transport system.

\section{FvbA is a ferric vibriobactin receptor in $P$. aeruginosa}

In order to identify the ferrivibriobactin transport system in $P$. aeruginosa, we examined the $P$. aeruginosa genome and searched for genes with high homology to the $V$. cholerae vibriobactin uptake system. We identified one ORF, PA4156, annotated as a probable TonB-dependent receptor (Pseudomonas Genome Project database) with $48 \%$ similarity to ViuA (Protein ID YP_001217728). ViuA is a $74 \mathrm{kDa}$ outer membrane protein that serves as a receptor for ferric vibriobactin in $V$. cholerae (Stoebner et al., 1992). Bioinformatic analysis revealed that the $P$. aeruginosa PA4156-encoded protein contained TonBdependent receptor characteristics, including an $\mathrm{N}$-terminal 'plug' domain (residues 55-171) and a predicted $\beta$ barrel structure. Therefore, we named the PA4156 gene $f v b A$ for ferric vibriobactin receptor. To test whether FvbA was responsible for vibriobactin uptake in $P$. aeruginosa, we constructed a triple mutant, PASE2 (PAO1 $p v d D \Delta p c h E F$ $f v b A::$ pSE4156IS), containing an insertion in the $f v b A$ gene in the background of the PASE1 siderophoresdeficient mutant and examined the effect of vibriobactin on its growth in iron-deficient medium. Similar to the parent strain PASE1, PASE2 grew in M9 medium and failed to grow in M9 containing EDDA. However, unlike the parental strain, vibriobactin was unable to restore the growth of PASE2 (Fig. 1, white bars), suggesting that FvbA is indeed required for vibriobactin utilization in $P$. aeruginosa. In support, complementation of the $f v b A$ mutation in trans restored the ability of the PASE3 mutant strain to utilize vibriobactin (Fig. 1, striped bars).

In addition to the siderophore-specific outer membrane receptor, there are periplasmic and inner membrane proteins responsible for the transport of the ferric siderophores across the periplasm and the inner membrane. Interestingly, downstream of the $f v b A$ gene there is a gene cluster, the fepBDG operon (PA4159-PA4161) and the $f e p C$ gene (PA4158), which are annotated as genes that may be involved in ferric enterobactin utilization. The FepB and FepC proteins in E. coli have been shown to be located in the periplasm and in the cytoplasmic membrane, respectively, and transport catecholate ferric siderophores (Pierce \& Earhart, 1986). Since both enterobactin and vibriobactin belong to the catecholate siderophore family, we examined the involvement of these genes in vibriobactin uptake. For this we used the PASE1 strain to construct a mutant carrying an insertion in the fepBDG operon. Growth in the presence of EDDA and vibriobactin

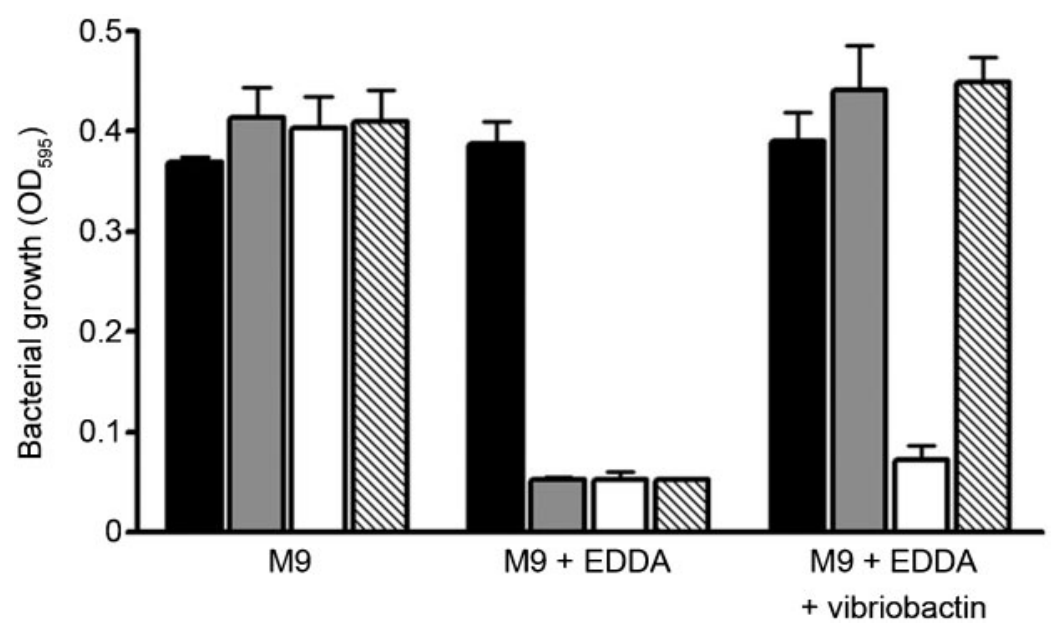

Fig. 1. Effect of vibriobactin on growth of $P$. aeruginosa strains in iron-deficient conditions. $P$. aeruginosa strains PAO1 (black bars), PASE1 (grey bars), PASE2 (white bars) and fvbA complemented mutant PASE3 (hatched bars) were grown overnight on $\mathrm{M} 9$ minimal medium with or without $25 \mu \mathrm{g}$ EDDA ml ${ }^{-1}$ or $25 \mu \mathrm{g}$ EDDA $\mathrm{ml}^{-1}$ and $2.5 \mu \mathrm{g}$ vibriobactin $\mathrm{ml}^{-1}$. All cultures were incubated at $37{ }^{\circ} \mathrm{C}$ with shaking (250 r.p.m.). Bacterial growth ( $\left.\mathrm{OD}_{595}\right)$ was measured after $12 \mathrm{~h}$. Error bars, SD. 
was not impaired in this mutant (data not shown), suggesting either that this gene cluster is not involved in vibriobactin uptake or that there is a redundancy in these uptake systems.

\section{The fvbA promoter contains a Fur binding sequence}

Our next goal was to understand how $f v b A$ expression is regulated in the bacterium. Many of the iron-regulated genes are controlled by the ferric uptake regulator (Fur), a repressor that responds to the intracellular iron concentration. Under iron-replete conditions, Fur binds Fe(II), undergoes changes in configuration and binds to specific promoter sequences, 19 bp long, known as Fur boxes (Escolar et al., 1999). Sideropore receptors are among the Fur-regulated genes in $P$. aeruginosa; moreover, the promoter region of PA4156 has been demonstrated to contain a Fur binding consensus sequence (van Oeffelen et al., 2008). In order to determine whether this putative Fur box (Fig. 2a) is functional we performed the FURTA (Stojiljkovic et al., 1994). In this assay an enterobactindeficient E. coli strain carrying a fhuF: : lacZ chromosomal fusion with low affinity for Fur-Fe(II) was used as a surrogate; the presence of a high-copy plasmid with a Fur binding site titrates out the Fur pool, resulting in derepression of $f h u F:$ : lac $Z$ and in a $\mathrm{Lac}^{+}$phenotype (Stojiljkovic et al., 1994). We examined two constructs, one with the full-length $f v b A$ promoter containing the putative Fur box (ECSE1) and one with a truncated promoter, missing this motif (ECSE2). The ECSE1 strain carrying $f v b A$ full-length promoter demonstrated a red colony phenotype $\left(\mathrm{Lac}^{+}\right)$at iron concentrations up to $120 \mu \mathrm{M}$, indicating that the Fur protein can bind the $f v b A$ promoter (Fig. 2b). The ECSE2 strain carrying a truncated $f v b A$ promoter without the Fur predicted sequence displayed a $\mathrm{Lac}^{+}$phenotype at iron concentrations lower than $40 \mu \mathrm{M}$ (similar to the negative control strain), indicating that the Fur protein was unable to bind the truncated promoter (Fig. 2b). These results demonstrate that the predicted Fur box sequence indeed serves as the Fur binding site in the $f v b A$ promoter. As a positive control we used the $p v d S$ promoter region. PvdS is an ECF sigma factor that is required for pyoverdine synthesis and is known to be repressed under iron-replete conditions due to the presence of a Fur binding sequence in its promoter region (Cunliffe et al., 1995). This construct showed a strong $\mathrm{Lac}^{+}$phenotype even at iron concentrations above $150 \mu \mathrm{M}$. Therefore, we conclude that the Fur box of $f v b A$ is most likely not a strong Fur binding sequence.

\section{Vibriobactin specifically induces $f v b A$ expression}

The presence of a Fur box in the regulatory region of the $f v b A$ gene suggests that iron availability affects its expression. Using real-time PCR we examined the effect of iron on $f v b A$ expression. As a control, we also examined the expression of $p v d S$. Consistent with previous data, both (a)
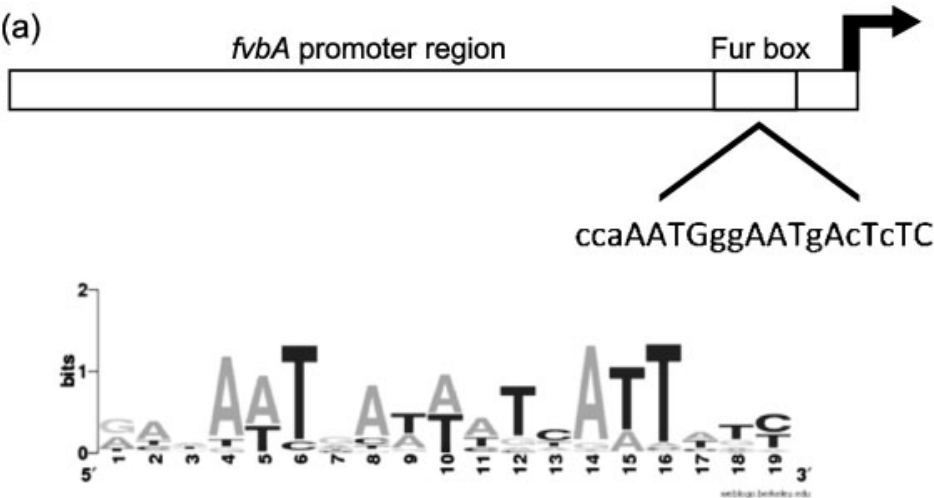

(b)

\begin{tabular}{|l|c|}
\hline $\begin{array}{l}\text { Strain/ } \\
\text { construct }\end{array}$ & $\begin{array}{c}\text { Lac }^{+} \text {phenotype } \\
\left(\mathrm{FeCl}_{3} \mathbf{)}\right.\end{array}$ \\
\hline $\begin{array}{l}\mathrm{P}_{\text {pvds }} \text { positive } \\
\text { control }\end{array}$ & $\geq 150 \mu \mathrm{M}$ \\
\hline $\begin{array}{l}\mathrm{H} 1717 \text { negative } \\
\text { control }\end{array}$ & $\leq 40 \mu \mathrm{M}$ \\
\hline $\begin{array}{l}\text { fvbA full-length } \\
\text { promoter }\end{array}$ & $\leq 120 \mu \mathrm{M}$ \\
\hline $\begin{array}{l}\text { fvbA truncated } \\
\text { promoter }\end{array}$ & $\leq 40 \mu \mathrm{M}$ \\
\hline
\end{tabular}

Fig. 2. Characterization of a Fur box in the $f v b A$ promoter region. (a) Fur consensus sequence predicted in the $f v b A$ promoter region. The Fur consensus sequence logo was derived from Fur binding sites of 36 ironcontrolled genes in $P$. aeruginosa identified by microarray studies. Letter heights indicate the frequency with which a given base is represented at each position. The $f v b A$ putative Fur box is presented below the schematic. Uppercase type represents residues that match the base in the corresponding position within the Fur consensus sequence. (b) FURTA. H1717 E. coli strains containing the $f v b A$ putative fulllength promoter region or a truncated promoter without the Fur box were grown on MacConkey lactose agar plates supplemented with $100 \mu \mathrm{M}$ ampicillin and 20,40, 50, 60, 70, 120 or $150 \mu \mathrm{M} \mathrm{FeCl}_{3}$. E. coli strain $\mathrm{H} 1717$ containing the pvdS promoter was used as a positive control, and $\mathrm{H} 1717$ alone as a negative control. Plates were incubated overnight at $37{ }^{\circ} \mathrm{C}$ and LacZ activity was determined by colony colour (red for $\mathrm{Lac}^{+}$and white for $\mathrm{Lac}^{-}$). 
$p v d S$ and $f v b A$ were repressed, 17 - and 1.5-fold, respectively, when iron was added to the medium $(100 \mu \mathrm{M}$; Fig. $3)$. The fairly low repression by iron of $f v b A$ expression supports the results obtained with the FURTA assay, suggesting a weak Fur box. However, in some cases, the siderophore itself can act as a signal for the expression of its cognate receptor. For example, the expression of pyoverdine uptake genes is enhanced in the presence of pyoverdine (Beare et al., 2003), and pfeA expression is activated by enterobactin (Dean \& Poole, 1993). To examine whether $f v b A$ expression can also be induced by the siderophore itself, we measured the transcript level of $f v b A$ in the presence of vibriobactin ( $p v d S$ expression was also examined as a control). The expression of $f v b A$ was not altered by the addition of EDDA, but was induced 12-fold when vibriobactin was added (Fig. 3). These results show that $f v b A$ is specifically induced in the presence of vibriobactin. Supporting these findings, similar results were observed with an $f v b A$ promoter fusion to GFP (see Supplementary Fig. S1). As expected, pvdS expression was induced 2.6-fold in the presence of EDDA. However, the addition of vibriobactin resulted in an approximately fivefold reduction in $p v d S$ transcript levels, further indicating that in the presence of vibriobactin, $P$. aeruginosa is able to efficiently obtain iron from the environment (Fig. 3). To further characterize the $f v b A$-specific response to vibriobactin, we used a $f v b A$ promoter fusion to GFP to test the ability of different siderophores to induce $f v b A$

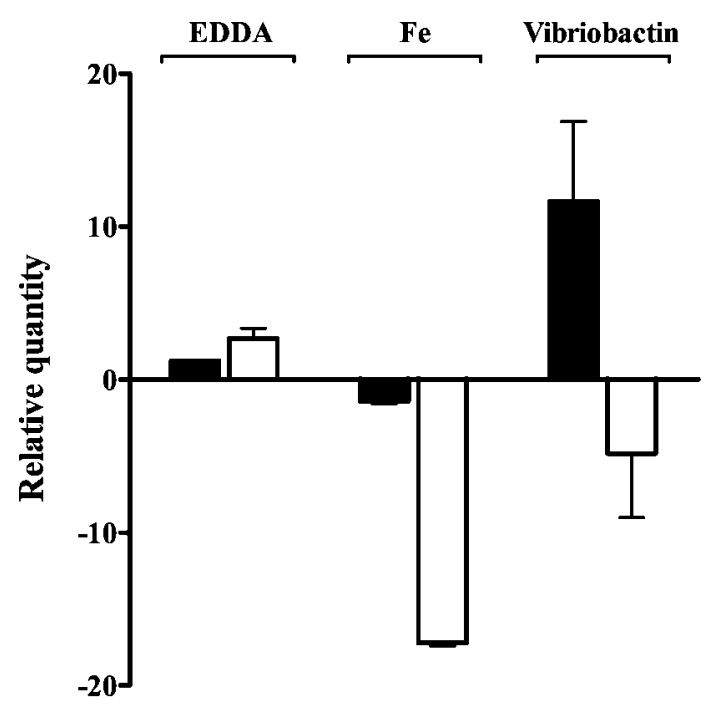

Fig. 3. Vibriobactin induces $f v b A$ expression in $P$. aeruginosa. $P$. aeruginosa mutant strain PASE1 was grown in M9 to the midexponential phase $\left(O_{595} 0.5\right)$ and then exposed for $3 \mathrm{~h}$ to the following conditions: $\mathrm{M} 9, \mathrm{M} 9+\operatorname{EDDA}\left(25 \mu \mathrm{g} \mathrm{ml}{ }^{-1}\right), \mathrm{M} 9+\mathrm{FeCl}_{3}$ $(100 \mu \mathrm{M})$ and $\mathrm{M} 9+$ vibriobactin $\left(2.5 \mu \mathrm{g} \mathrm{ml}^{-1}\right)$. Total RNA was isolated and the relative quantities of $f v b A$ (black bars) and $p v d S$ (white bars) transcripts were measured using real-time PCR. PA1684 was used as a housekeeping reference gene and M9 alone was used as the reference condition. Error bars, SD. expression. Generally, siderophores can be divided into three major groups according to their chemical structure: hydroxamate siderophores (including aerobactin, ferrichrome and deferoxamine), catecholate siderophores (including vibriobactin and enterobactin) and carboxylate siderophores (Miethke \& Marahiel, 2007). As can be seen in Fig. 4, none of the tested siderophores, except for vibriobactin, was able to induce the expression of $f v b A$. This also included enterobactin, which, similarly to vibriobactin, belongs to the catecholate siderophore family. Furthermore, while enterobactin was able to induce the expression of its cognate receptor, $p f e A$ (Supplementary Fig. S2), no change in $p f e A$ transcript levels was observed in the presence of vibriobactin (data not shown). Our results support the hypothesis that despite the fact that both enterobactin and vibriobactin are catecholate siderophores, they seem to have distinct uptake systems in P. aeruginosa. Ghysels and colleagues have shown that a $P$. aeruginosa double mutant in the two enterobactin receptors, $p f e A$ (PA2688) and pirA (PA0931), fails to utilize enterobactin as an iron source (Ghysels et al., 2005), indicating that there is no additional enterobactin uptake system in the genome. Likewise, here we showed that $f v b A$ expression was not induced by enterobactin (Fig. 4), and that the two enterobactin-uptake systems (i.e. PfeA and PirA, which are intact in our triple mutant PASE2) cannot support vibriobactin uptake.

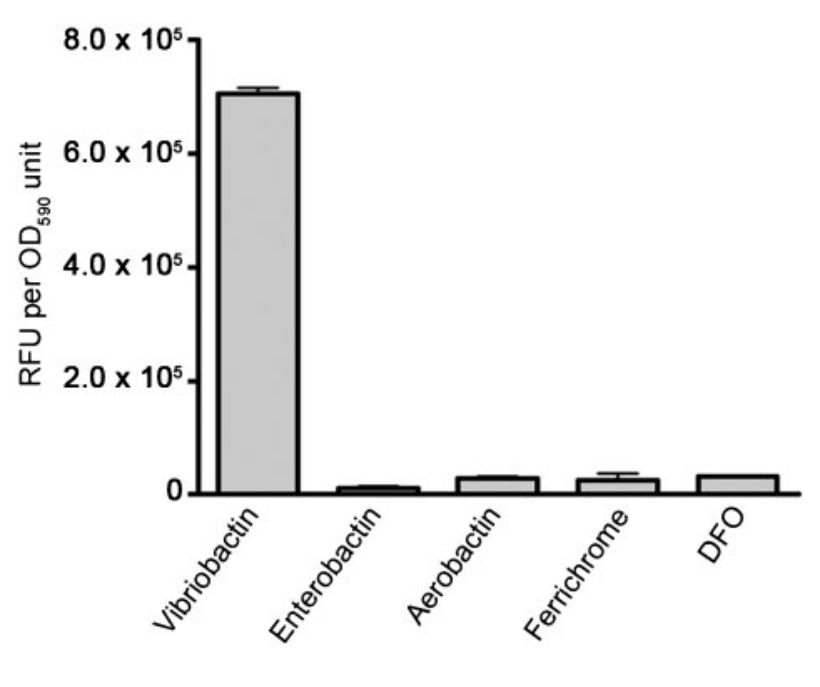

Fig. 4. Siderophore-mediated FvbA expression in $P$. aeruginosa. $P$. aeruginosa mutant strain PASE4 carrying a chromosomal $f v b A$ promoter-gfp fusion was grown in $\mathrm{M} 9$ to the mid-exponential phase $\left(\mathrm{OD}_{595} \mathrm{0.5}\right)$ and then exposed for $4 \mathrm{~h}$ to different siderophores: vibriobactin, enterobactin, aerobactin, ferrichrome or deferoxamine (DFO). fvbA expression was assessed by measuring fluorescence. The specific activity, i.e. relative fluorescence units (RFU) versus growth $\left(\mathrm{OD}_{595}\right)$, was determined, and the fold change in specific activity in response to siderophore addition is presented. Error bars, SD. 


\section{FvbR is involved in $f v b A$ regulation}

The expression of $f v b A$ is induced in the presence of vibriobactin; however, a multiple sequence alignment with similar ferric siderophore receptors revealed that the FvbA receptor lacks the N-terminal extension (data not shown), a typical feature of TonB receptors involved in signal transduction. Since this region has been shown to take part in receptor-dependent gene expression (Noinaj et al., 2010), the autoregulation of FvbA by the canonical sigma/ anti-sigma factor is highly unlikely. Interestingly, the adjacent gene downstream to $f v b A$, PA4157, is annotated as a probable transcriptional regulator of the IclR family and contains a helix-turn-helix DNA binding motif in the $\mathrm{N}$-terminal domain. Members of the IclR family are known to regulate diverse metabolic processes, including glycerol metabolism in Streptomyces avermitilis (Bolotin \& Biro, 1990), degradation of acyl-homoserine lactones in Agrobacterium tumefaciens (Zhang et al., 2004), catabolism of aromatic acids in Pseudomonas (Arias-Barrau et al., 2004) and catechol catabolism in Rhodococcus opacus (Eulberg \& Schlömann, 1998). The IclR regulators are very diverse and can act as activators or repressors, or can have a dual transcriptional activity (for a review, see Molina-Henares et al., 2006).

In order to examine the possible involvement of PA4157 in the regulation of $f v b A$, we measured transcript levels of $f v b A$ in the wild-type strain and the PA4157 mutant strain (PASE5) in the presence or absence of vibriobactin. Previously, we observed a 12 -fold induction in $f_{v} b A$ expression in the presence of vibriobactin in the PASE1 mutant (Fig. 3). Real-time PCR analysis showed that vibriobactin was also able to induce $f v b A$ expression in the wild-type strain, although to a lesser extent (Fig. 5a). Interestingly, the expression of $f v b A$ in the PA4157 mutant remained high, independently of the presence of vibriobactin in the medium, suggesting that PA4157 plays a role in the regulation of $f v b A$ and may act as a repressor (Fig. $5 a)$. Based on these results, we termed PA4157 FvbR for ferric vibriobactin regulator. To further understand the involvement of Fvbr in $f v b A$ regulation, we used the PASE1 mutant to construct strains that either overexpressed or were defective in $f v b R$ and examined their ability to utilize vibriobactin for growth. The ability of the PASE7 triple mutant to utilize vibriobactin was intact (Fig. $5 b$ ); however, overexpression of $f v b R$ resulted in complete growth inhibition of this strain, despite the presence of vibriobactin in the medium (Fig. 5b), a phenotype similar to that of the PASE2 mutant strain (Fig. 1). These results further support the real-time PCR analysis that suggested that FvbR acts as a repressor of $f v b A$ transcription. To further understand the mechanism of $f v b A$ regulation we examined the expression of $f v b R$ in the presence of vibriobactin by real-time PCR. Surprisingly, the expression of $f v b R$ was induced more than threefold in the presence of vibriobactin (data not shown). We hypothesize that perhaps vibriobactin acts as an effector and titrates out FvbR, allowing the expression of $f v b A$ and utilization of (a)

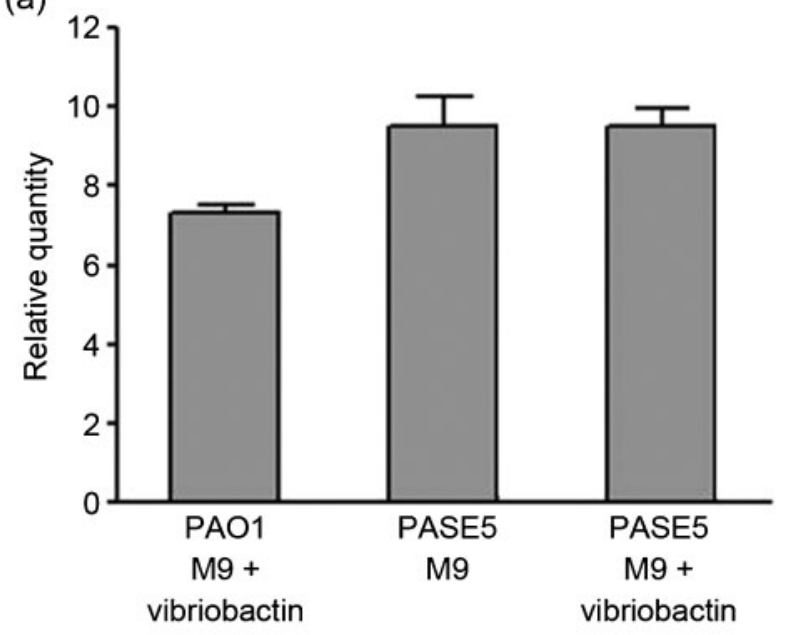

(b)

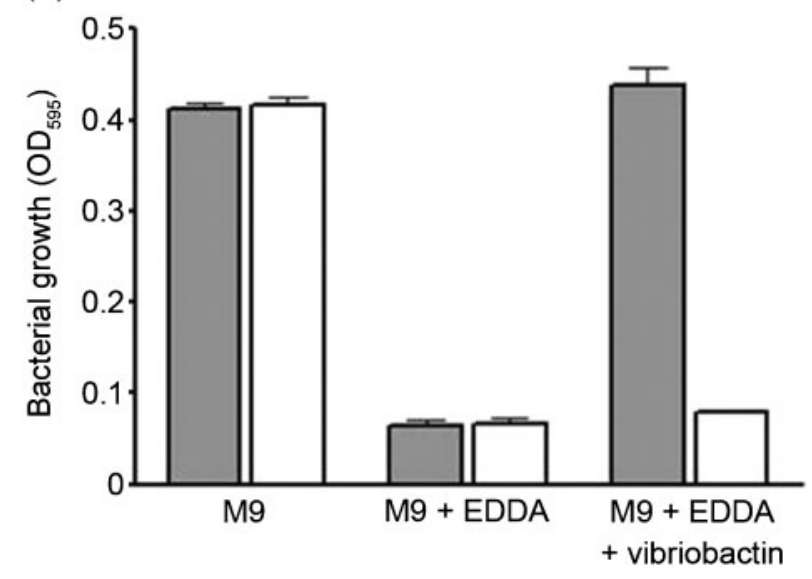

Fig. 5. Involvement of FvbR in $f v b A$ regulation. (a) Effect of $f v b R$ on $f v b A$ expression. $P$. aeruginosa PAO1 and $f v b R$ mutant strain PASE5 were grown in $\mathrm{M} 9$ to the mid-exponential phase $\left(\mathrm{OD}_{595}\right.$ $0.5)$ and then were exposed for $3 \mathrm{~h}$ to the following conditions: M9 or M9 containing vibriobactin $\left(2.5 \mu \mathrm{g} \mathrm{ml} \mathrm{m}^{-1}\right)$. Total RNA was isolated and the relative quantity of $f v b A$ transcripts was measured using real-time PCR. PA1684 was used as a housekeeping reference gene and PAO1 grown in $\mathrm{M} 9$ alone was used as the reference condition. Error bars, SD. (b) Effect of $f v b R$ mutation and overexpression on the utilization of vibriobactin in iron-deficient conditions. $P$. aeruginosa triple mutant strain PASE7 (grey bars) and $f v b R$ overexpression strain PASE6 (white bars) were grown overnight on M9 minimal medium with or without $25 \mu \mathrm{g}$ EDDA $\mathrm{ml}^{-1}$ or $25 \mu \mathrm{g}$ EDDA $\mathrm{ml}^{-1}$ and $2.5 \mu \mathrm{g}$ vibriobactin $\mathrm{ml}^{-1}$. All cultures were incubated at $37{ }^{\circ} \mathrm{C}$ with shaking (250 r.p.m.). Bacterial growth $\left(\mathrm{OD}_{595}\right)$ was measured after $12 \mathrm{~h}$. Error bars, SD.

iron for growth. When vibriobactin levels fall below a certain threshold, FvbR is no longer titrated and can then act as a repressor of $f v b A$. This mechanism can allow finetuning and increased sensitivity to changes in vibriobactin concentrations. The regulation of IclR transcriptional activity by small molecules has been reported in several 
bacterial species and in different metabolic pathways (Molina-Henares et al., 2006). In fact, many IclR-type regulators contain a small molecule effector binding domain at their $\mathrm{C}$ terminus; however, only a few effectors have been identified. For example, the IclR transcriptional regulator in E. coli recognizes two antagonist ligands and can act as a corepressor (upon pyruvate binding) or activator (upon glyoxylate binding) of the glyoxylate bypass operon (Lorca et al., 2007). To the best of our knowledge this is the first report of an IclR-like regulator involved in iron uptake, and future work will be required to establish its mode of regulation.

\section{ACKNOWLEDGEMENTS}

The work was supported by the Israel Science Foundation grant number 366/07 to E. B. We would like to thank Dr Chaim Wachtel and Dr Hiba Waldman Ben-Asher for technical assistance and fruitful discussion. We thank Professor K. Hantke, University of Tübingen, for providing the FURTA strains used in this study. This research is part of the requirements for a $\mathrm{PhD}$ thesis for $\mathrm{S}$. E. at Bar Ilan University.

\section{REFERENCES}

Ankenbauer, R. G. \& Quan, H. N. (1994). FptA, the Fe(III)-pyochelin receptor of Pseudomonas aeruginosa: a phenolate siderophore receptor homologous to hydroxamate siderophore receptors. J Bacteriol 176, 307-319.

Ankenbauer, R., Hanne, L. F. \& Cox, C. D. (1986). Mapping of mutations in Pseudomonas aeruginosa defective in pyoverdin production. J Bacteriol 167, 7-11.

Arias-Barrau, E., Olivera, E. R., Luengo, J. M., Fernández, C., Galán, B., García, J. L., Díaz, E. \& Miñambres, B. (2004). The homogentisate pathway: a central catabolic pathway involved in the degradation of L-phenylalanine, L-tyrosine, and 3-hydroxyphenylacetate in Pseudomonas putida. J Bacteriol 186, 5062-5077.

Banin, E., Vasil, M. L. \& Greenberg, E. P. (2005). Iron and Pseudomonas aeruginosa biofilm formation. Proc Natl Acad Sci U S A 102, 11076-11081.

Beare, P. A., For, R. J., Martin, L. W. \& Lamont, I. L. (2003). Siderophore-mediated cell signalling in Pseudomonas aeruginosa: divergent pathways regulate virulence factor production and siderophore receptor synthesis. Mol Microbiol 47, 195-207.

Bolotin, A. \& Biro, S. (1990). Nucleotide sequence of the putative regulatory gene and major promoter region of the Streptomyces griseus glycerol operon. Gene 87, 151-152.

Braun, V. \& Hantke, K. (2011). Recent insights into iron import by bacteria. Curr Opin Chem Biol 15, 328-334.

Braun, V., Mahren, S. \& Sauter, A. (2005). Gene regulation by transmembrane signaling. Biometals 18, 507-517.

Choi, K. H. \& Schweizer, H. P. (2006). mini-Tn7 insertion in bacteria with single att $\operatorname{Tn} 7$ sites: example Pseudomonas aeruginosa. Nat Protoc 1, 153-161.

Chu, B. C., Garcia-Herrero, A., Johanson, T. H., Krewulak, K. D., Lau, C. K., Peacock, R. S., Slavinskaya, Z. \& Vogel, H. J. (2010), Siderophore uptake in bacteria and the battle for iron with the host; a bird's eye view. Biometals 23, 601-611.

Cornelis, P. \& Matthijs, S. (2002). Diversity of siderophore-mediated iron uptake systems in fluorescent pseudomonads: not only pyoverdines. Environ Microbiol 4, 787-798.
Cornelis, P., Matthijs, S. \& Van Oeffelen, L. (2008). Iron uptake regulation in Pseudomonas aeruginosa. Biometals 22, 15-22.

Covarrubias, L. \& Bolivar, F. (1982). Construction and characterization of new cloning vehicles. VI. Plasmid pBR329, a new derivative of pBR328 lacking the 482-base-pair inverted duplication. Gene 17, 7989.

Cox, C. D. (1980). Iron uptake with ferripyochelin and ferric citrate by Pseudomonas aeruginosa. J Bacteriol 142, 581-587.

Cox, C. D. \& Adams, P. (1985). Siderophore activity of pyoverdin for Pseudomonas aeruginosa. Infect Immun 48, 130-138.

Cuiv, P. O., Clarke, P. \& O’Connell, M. (2006). Identification and characterization of an iron-regulated gene, cht $A$, required for the utilization of the xenosiderophores aerobactin, rhizobactin 1021 and schizokinen by Pseudomonas aeruginosa. Microbiology 152, 945-954.

Cunliffe, H. E., Merriman, T. R. \& Lamont, I. L. (1995). Cloning and characterization of $p v d S$, a gene required for pyoverdine synthesis in Pseudomonas aeruginosa: PvdS is probably an alternative sigma factor. J Bacteriol 177, 2744-2750.

de Lorenzo, V. \& Timmis, K. N. (1994). Analysis and construction of stable phenotypes in Gram-negative bacteria with Tn5- and Tn10derived minitransposons. Methods Enzymol 235, 386-405.

Dean, C. R. \& Poole, K. (1993). Cloning and characterization of the ferric enterobactin receptor gene ( $p f e A$ ) of Pseudomonas aeruginosa. J Bacteriol 175, 317-324.

Escolar, L., Pérez-Martín, J. \& de Lorenzo, V. (1999). Opening the iron box: transcriptional metalloregulation by the Fur protein. J Bacteriol 181, 6223-6229.

Eulberg, D. \& Schlömann, M. (1998). The putative regulator of catechol catabolism in Rhodococcus opacus 1CP-an IclR-type, not a LysR-type transcriptional regulator. Antonie van Leeuwenhoek 74, 7182.

Ghysels, B., Ochsner, U., Möllman, U., Heinisch, L., Vasil, M., Cornelis, P. \& Matthijs, S. (2005). The Pseudomonas aeruginosa pirA gene encodes a second receptor for ferrienterobactin and synthetic catecholate analogues. FEMS Microbiol Lett 246, 167-174.

Griffiths, G. L., Sigel, S. P., Payne, S. M. \& Neilands, J. B. (1984). Vibriobactin, a siderophore from Vibrio cholerae. J Biol Chem 259, 383-385.

Heinrichs, D. E. \& Poole, K. (1996). PchR, a regulator of ferripyochelin receptor gene $(f p t A)$ expression in Pseudomonas aeruginosa, functions both as an activator and as a repressor. J Bacteriol 178, 2586-2592.

Hoang, T. T., Karkhoff-Schweizer, R. R., Kutchma, A. J. \& Schweizer, H. P. (1998). A broad-host-range Flp-FRT recombination system for site-specific excision of chromosomally-located DNA sequences: application for isolation of unmarked Pseudomonas aeruginosa mutants. Gene 212, 77-86.

Hoang, T. T., Kutchma, A. J., Becher, A. \& Schweizer, H. P. (2000). Integration-proficient plasmids for Pseudomonas aeruginosa: sitespecific integration and use for engineering of reporter and expression strains. Plasmid 43, 59-72.

Hoegy, F., Lee, X., Noel, S., Rognan, D., Mislin, G. L., Reimmann, C. \& Schalk, I. J. (2009). Stereospecificity of the siderophore pyochelin outer membrane transporters in fluorescent pseudomonads. J Biol Chem 284, 14949-14957.

Holloway, B. W., Krishnapillai, V. \& Morgan, A. F. (1979). Chromosomal genetics of Pseudomonas. Microbiol Rev 43, 73-102.

Jacobs, M. A., Alwood, A., Thaipisuttikul, I., Spencer, D., Haugen, E., Ernst, S., Will, O., Kaul, R., Raymond, C. \& other authors (2003). Comprehensive transposon mutant library of Pseudomonas aeruginosa. Proc Natl Acad Sci U S A 100, 14339-14344. 
Leoni, L., Ciervo, A., Orsi, N. \& Visca, P. (1996). Iron-regulated transcription of the $p v d A$ gene in Pseudomonas aeruginosa: effect of Fur and PvdS on promoter activity. J Bacteriol 178, 2299-2313.

Llamas, M. A., Sparrius, M., Kloet, R., Jiménez, C. R., Vandenbroucke-Grauls, C. \& Bitter, W. (2006). The heterologous siderophores ferrioxamine $\mathrm{B}$ and ferrichrome activate signaling pathways in Pseudomonas aeruginosa. J Bacteriol 188, 1882-1891.

Llamas, M. A., Mooij, M. J., Sparrius, M., Vandenbroucke-Grauls, C. M., Ratledge, C. \& Bitter, W. (2008). Characterization of five novel Pseudomonas aeruginosa cell-surface signalling systems. Mol Microbiol 67, 458-472.

Lorca, G. L., Ezersky, A., Lunin, V. V., Walker, J. R., Altamentova, S., Evdokimova, E., Vedadi, M., Bochkarev, A. \& Savchenko, A. (2007). Glyoxylate and pyruvate are antagonistic effectors of the Escherichia coli IclR transcriptional regulator. J Biol Chem 282, 16476-16491.

Meyer, J. M. (1992). Exogenous siderophore-mediated iron uptake in Pseudomonas aeruginosa: possible involvement of porin OprF in iron translocation. J Gen Microbiol 138, 951-958.

Michel, L., Bachelard, A. \& Reimmann, C. (2007). Ferripyochelin uptake genes are involved in pyochelin-mediated signalling in Pseudomonas aeruginosa. Microbiology 153, 1508-1518.

Miethke, M. \& Marahiel, M. A. (2007). Siderophore-based iron acquisition and pathogen control. Microbiol Mol Biol Rev 71, 413-451.

Mislin, G. L., Hoegy, F., Cobessi, D., Poole, K., Rognan, D. \& Schalk, I. J. (2006). Binding properties of pyochelin and structurally related molecules to FptA of Pseudomonas aeruginosa. J Mol Biol 357, 14371448.

Molina-Henares, A. J., Krell, T., Eugenia Guazzaroni, M., Segura, A. \& Ramos, J. L. (2006). Members of the IclR family of bacterial transcriptional regulators function as activators and/or repressors. FEMS Microbiol Rev 30, 157-186.

Neilands, J. B. (1995). Siderophores: structure and function of microbial iron transport compounds. J Biol Chem 270, 26723-26726.

Newman, J. R. \& Fuqua, C. (1999). Broad-host-range expression vectors that carry the L-arabinose-inducible Escherichia coli araBAD promoter and the araC regulator. Gene 227, 197-203.

Noinaj, N., Guillier, M., Barnard, T. J. \& Buchanan, S. K. (2010). TonB-dependent transporters: regulation, structure, and function. Annu Rev Microbiol 64, 43-60.

Ochsner, U. A., Wilderman, P. J., Vasil, A. I. \& Vasil, M. L. (2002). GeneChip expression analysis of the iron starvation response in
Pseudomonas aeruginosa: identification of novel pyoverdine biosynthesis genes. Mol Microbiol 45, 1277-1287.

Palma, M., Worgall, S. \& Quadri, L. E. (2003). Transcriptome analysis of the Pseudomonas aeruginosa response to iron. Arch Microbiol 180, 374-379.

Pierce, J. R. \& Earhart, C. F. (1986). Escherichia coli K-12 envelope proteins specifically required for ferrienterobactin uptake. J Bacteriol 166, 930-936.

Poole, K., Neshat, S., Krebes, K. \& Heinrichs, D. E. (1993). Cloning and nucleotide sequence analysis of the ferripyoverdine receptor gene fpvA of Pseudomonas aeruginosa. J Bacteriol 175, 4597-4604.

Schalk, I. J. (2008). Metal trafficking via siderophores in Gramnegative bacteria: specificities and characteristics of the pyoverdine pathway. J Inorg Biochem 102, 1159-1169.

Schweizer, H. P. (1991). Escherichia-Pseudomonas shuttle vectors derived from pUC18/19. Gene 97, 109-112.

Skaar, E. P. (2010). The battle for iron between bacterial pathogens and their vertebrate hosts. PLoS Pathog 6, e1000949.

Stoebner, J. A., Butterton, J. R., Calderwood, S. B. \& Payne, S. M. (1992). Identification of the vibriobactin receptor of Vibrio cholerae. J Bacteriol 174, 3270-3274.

Stojiljkovic, I., Bäumler, A. J. \& Hantke, K. (1994). Fur regulon in Gram-negative bacteria. Identification and characterization of new iron-regulated Escherichia coli genes by a Fur titration assay. J Mol Biol 236, 531-545.

van Oeffelen, L., Cornelis, P., Van Delm, W., De Ridder, F., De Moor, B. \& Moreau, Y. (2008). Detecting cis-regulatory binding sites for cooperatively binding proteins. Nucleic Acids Res 36, e46.

Visca, P., Leoni, L., Wilson, M. J. \& Lamont, I. L. (2002). Iron transport and regulation, cell signalling and genomics: lessons from Escherichia coli and Pseudomonas. Mol Microbiol 45, 1177-1190.

Woodcock, D. M., Crowther, P. J., Doherty, J., Jefferson, S., DeCruz, E., Noyer-Weidner, M., Smith, S. S., Michael, M. Z. \& Graham, M. W. (1989). Quantitative evaluation of Escherichia coli host strains for tolerance to cytosine methylation in plasmid and phage recombinants. Nucleic Acids Res 17, 3469-3478.

Zhang, H. B., Wang, C. \& Zhang, L. H. (2004). The quormone degradation system of Agrobacterium tumefaciens is regulated by starvation signal and stress alarmone (p)ppGpp. Mol Microbiol 52, 1389-1401.

Edited by: W. J. Quax 